\title{
Fluoroscopy Neuro-Guided Endoscopic Removal of a Lost Ventricular Catheter in Hydrocephalic Girl with Staphylococcal Shunt Infection
}

\author{
Leszek Herbowski ${ }^{1 *}$, Regina Szydłowska ${ }^{2}$, Józef Rudnicki $^{2}$, Aleksandra Harat ${ }^{3}$, Leszek Sagan $^{4}$ \\ ${ }^{1}$ Neurosurgery Department, Public Provincial Hospital, Szczecin, Poland \\ ${ }^{2}$ Department of Pediatrics, Public Provincial Hospital, Szczecin, Poland \\ ${ }^{3}$ Nicolaus Copernicus University, Ludwik Rydygier Collegium Medicum, Bydgoszcz, Poland \\ ${ }^{4}$ Department of Neurosurgery, Pomeranian Medical University, Szczecin, Poland \\ Email: *1eszekherbowski@data.pl,mjrudniccy@wp.pl, ola.harat@cm.umk.pl, leszekm.sagan@gmail.com
}

Received May 3, 2012; revised June 5, 2012; accepted June 19, 2012

\begin{abstract}
In the text, the authors present a successful treatment of an 8-year-old hydrocephalic girl with retained infected ventricular catheter. Altogether, there have been 56 recorded cases of intraventricular catheter migration, including only 5 of infected shunt. In the case described, the first attempt to remove the lost catheter endoscopically was unsuccessful which was the reason for an inflammation's spread. Only by means of fluoroscopy-assisted endoscopy was it possible to remove the free-floating infected shunt drain from the lateral ventricle during another surgery. In order to prevent immediate or delayed infection complications, the authors postulate a complete removal of a retained ventricular catheter from every patient.
\end{abstract}

Keywords: Hydrocephalus; Ventricular Catheter; Catheter Migration; Shunt Infection; Fluoroscopy-Assisted Endoscopy; Shunt Removal

\section{Introduction}

Intraventricular migration of a proximal shunt drain is a very rare complication following shunt surgery. It is called "retained ventricular catheter" (RVC) by Vajramani et al. or "sink ventricular drain" by Nowosławska et al. [1,2]. Its incidence ranges from $0.1 \%$ to $0.4 \%$ [3]. In a paper published in 2005, Yamazaki and coworkers reported 15 cases of such complication for time period 1955-2004 [4]. Interestingly enough, an unusual case of ventricular catheter migration was also reported for a hydrocephalic dog [5]. Generally, it is necessary to remove a shunt in case of diagnosed neuroinfection, although any removals can be extremely difficult as in case of disconnected catheter described by Chen et al. [6]. Our objective is to report a case of hydrocephalic girl with infected retained ventricular catheter.

\section{Case Description}

On October 2nd, 2004 an 8-year-old girl born at 35 weeks' gestation was referred to the Neurosurgery and Neurotraumatology Department of the District Hospital of Szczecin (Poland) by the Pediatric Department. The

\footnotetext{
"Corresponding author.
}

diagnosis was bacterial meningitis (MRCNS) without clinical improvements after 10 days of intraventricular vankomycin treatment $(10 \mathrm{mg} /$ daily $)$. At the age of 12 days the girl had undergone the ventriculoperitoneal $\mathrm{Pu}-$ denz shunt implantation in the Neurosurgery Clinic of the Children's Memorial Health Institute (CZD) in Łódź (Poland) due to congenital hydrocephalus diagnosed at 28 weeks of pregnancy. Moreover, from birth she had had episodes of tachypnoe and tachycardia 2 - 3 times a week. Due to ventricular dilatation (Figure 1) and psychomotor development retardation (the girl could not walk, she could say single and simple words only) the patient had required a revision surgery performed on June 25th, 2004 at the Neurosurgery and Neurotraumatology Department of the District Hospital of Szczecin. The old intraventricular catheter, which had turned out to be disconnected, could not be found even by means of neuroendoscopy. It had been replaced with a new ventriculoperitoneal Delta shunt, introduced on the left side of the head. A cerebrospinal fluid sample taken from the ventricle had been normal and the culture negative. After the operation the girl had had a recurrent fever treated ambulatory with the use of antibiotics (azithromycin). Only in October did we find out that during the patient's 


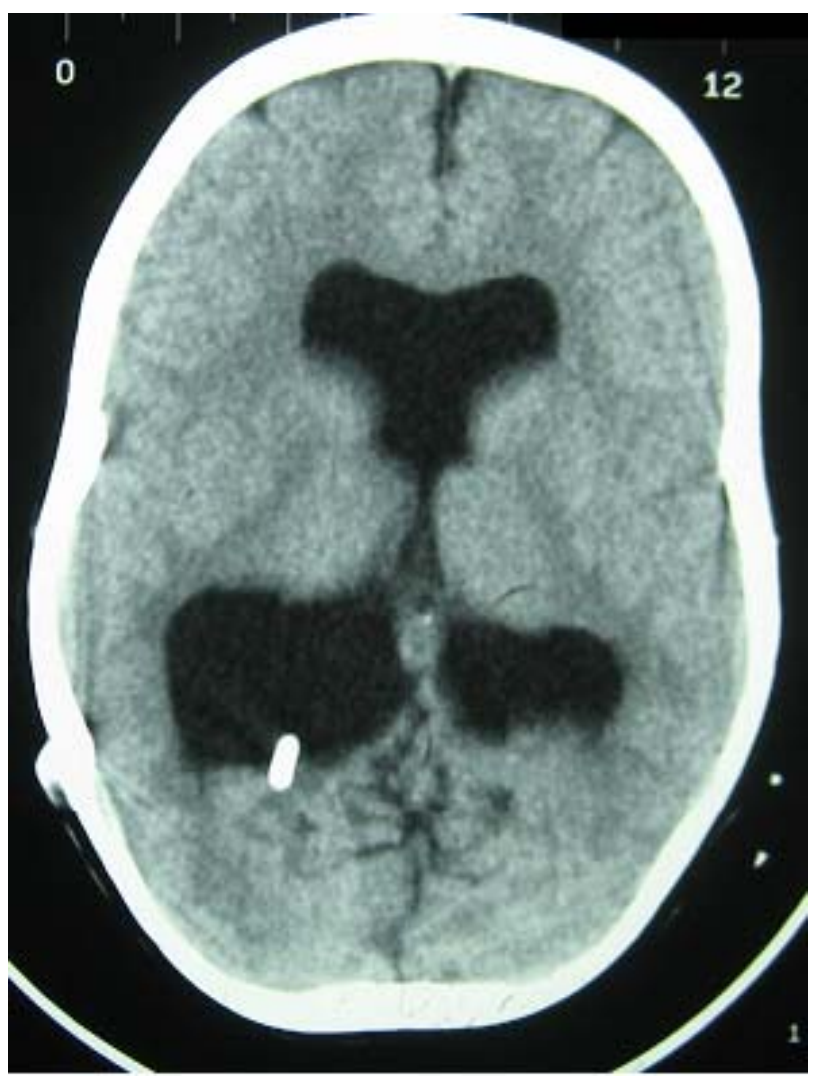

Figure 1. CT examination. Brain scan shows enlarged ventricular system. A shunt tap is located within the occipital horn of the right lateral ventricle.

stay in the Neurosurgery Department in June there had been nasal Staphylococcus aureus present. On the day of admission to the Pediatric Department (August 29th, 2004) the girl had shown symptoms of meningitis: she had been in a state of lethargy, she had had nuchal rigidity. Consequently, the lumbar puncture had been performed and cerebrospinal fluid collected. The examination of cerebrospinal fluid had revealed 107 lymphocytes in $1 \mathrm{~mm}^{3}$, 98 granulocytes in $1 \mathrm{~mm}^{3}$, total protein $-39.9 \mathrm{mg} / \mathrm{dl}$, glucose $-51 \mathrm{mg} / \mathrm{dl}$, chlorides $-122.2 \mathrm{mmol} / \mathrm{l}$. The methicillin-resistant coagulase-negative Staphylococcus epidermidis (MRCNS) had been identified. As a result, intraventricular antimicrobial therapy had started, but despite 10 days of vancomycin treatment (10 $\mathrm{mg}$ daily) there had been no clinical improvement.

On admission to the Neurosurgery and Neurotraumatology Department in October the neuroendoscopicallyassisted shunt removal was performed, but still the old intraventricular catheter could not be found. Due to intracranial hypertension and ventricular dilatation the external shunting was done and a 10-day linezolid therapy $(130 \mathrm{mg} \times 3$ i.v. $)$ started. The cerebrospinal fluid culture was positive for Enterobacter cloacae and therefore, according to bacterial susceptibility, Meronem was used.
Because of this cerebrospinal reinfection we decided to combine fluoroscopy-guided navigation with neuroendoscopy in order to find and remove the intraventricular catheter (Figure 2) of the old shunt, which proved to be successful. After the operation the control examination of cerebrospinal fluid was normal and the culture negative. Two weeks later a new ventriculoperitoneal Delta shunt with antisiphon device was implanted. The girl was cured both clinically and microbiologically. Control CT after 5 years (2009) does not show signs of hydrocephalus any longer (Figure 3).

Seven years later, in 2011, the girl is in a good clinical condition, she can walk herself and say single words like: "mother", "drink"; she can also communicate nonverbally. The episodes of tachypnoe and tachycardia disappeared completely after intraventricular catheter removal and a new shunt placement.

\section{Discussion}

The authors analyzed several papers concerning intraventricular migration of the shunt catheter. Altogether, there have been 56 recorded cases of intraventricular catheter migration, including those described by Yamazaki and the case presented in this paper [1,4,6-19]. What needs to be mentioned is the fact that Yamazaki and coworkers overlooked two cases of migrated and infected drain which were published in 1999 by Shingadia et al. and in 2003 by Vougioukas et al. [4,18,19]. Among all the cases, most patients are children, whereas only 5 patients $(9 \%)$ are adults. A special group of 23 pediatric patients was reported by Chen et al., who attributed ventricular catheter disconnection to a new type of shunt implanted between 2004 and 2009 [6]. There are several

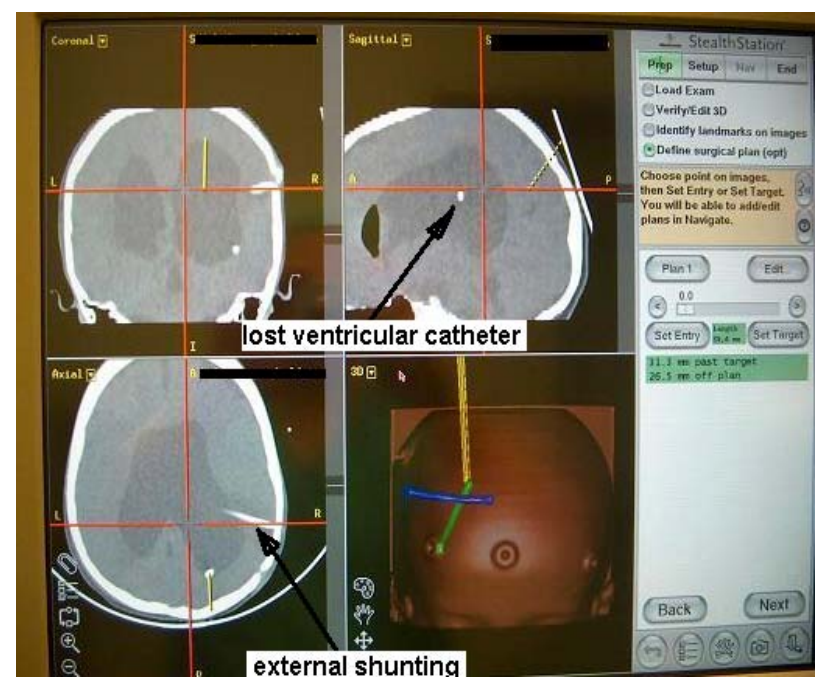

Figure 2. The image taken from navigation system. The "sink" drain of the old shunt is located within the right lateral ventricle. The second catheter is an external shunting. 


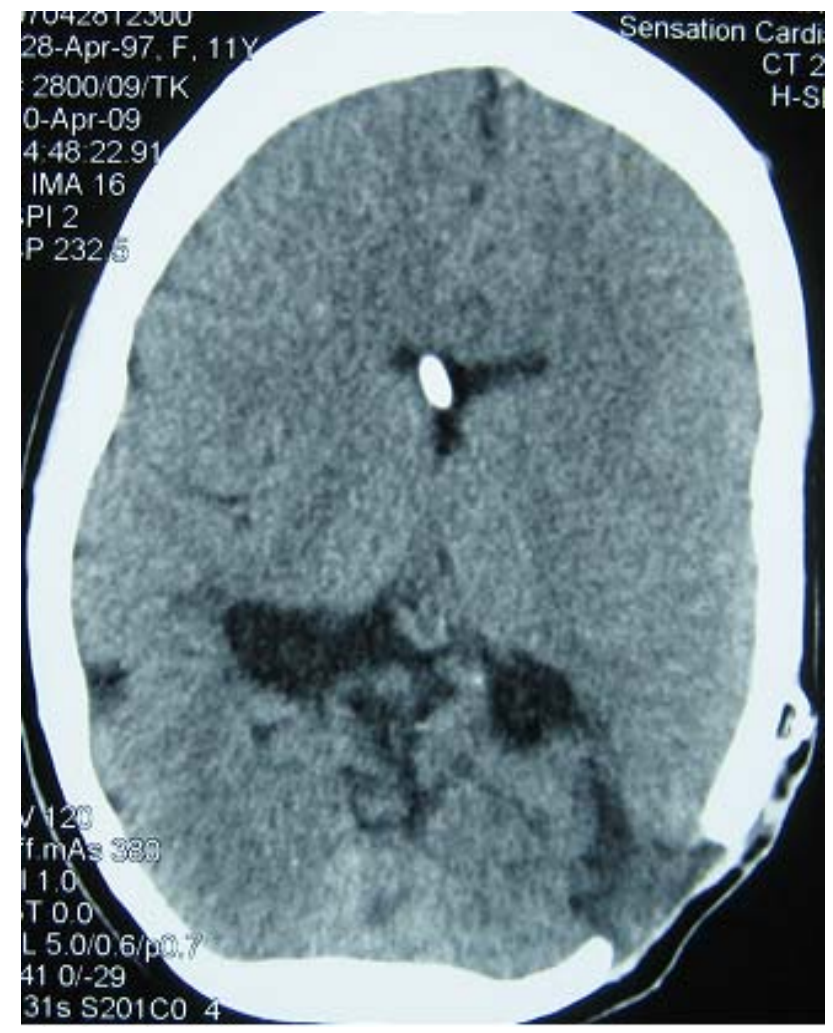

Figure 3. CT scan obtained 5 years after new shunt placement shows that the ventricles are of normal size and catheter tip is located at the desired location in the frontal horn of the lateral ventricle just close to the foramen of Monro.

factors responsible for intraventricular catheter migration such as technical fault, negative pressure gradient between cranial and abdominal cavity, neck flexion/extension movements ("windlass" effect) and patient growth. Sometimes the problem is minimized just to shunt failure as in the series presented by Chen et al. [6]. At the same time, Komolafe and coworkers recommend paying special attention to surgical details such as minimal diameter of the burr hole and cruciate instead of linear dural incision [10].

In terms of migrated catheter removal some authors consider the use of endoscopic technique $[2,11]$. On the other hand, Chen et al. do not recommend elective removal of retained ventricular catheter in asymptomatic patients [6]. Among all 56 patients already mentioned there have been only 8 cases $(14.5 \%)$ in which the catheter could not be removed surgically, although the rest of the authors did not describe in detail the extraction procedure. In our case the first attempt to remove the lost catheter endoscopically was unsuccessful and it was the reason for the inflammation's spread. In the second attempt conducted by means of of fluoroscopy-assisted endoscopy it was possible to remove the free-floating infected shunt drain from the lateral ventricle.

Insertion of percutaneous prosthetic grafts involves the risk of Staphylococcus epidermidis adherence to the wall of catheter and forming a biofilm. Shunt infection is the main complication which occurs from $1 \%$ to $41 \%$ of the cases in shunt surgery [20]. In a series of 570 shunt standard procedures in pediatric patients at the Johns Hopkins Hospital between 1997 and 2007 the percentage of infections equaled $11.2 \%$ [21]. The most common pathogen is gram-positive bacteria, especially Staphylococcal species $[20,21]$. The complete removal of infected shunt is essential in order to cure neuroinfection and avoid infection recurrence. Unless the infected catheter is removed, we can expect the seeding of pathogens and development of inflammation in place where Staphylococcus exists as in the case described here.

Within the list of 56 cases of catheter migration there are only five cases of infected shunt: a case of 23-year-old female reported by Vajramani et al., a case of 3-year-old boy by Shingadia et al., a case of 37-year-old male by Khan et al., a case of 16-year-old boy by Vougioukas et al. and a case of 8-year-old girl presented here $[1,9,18,19]$. In the case reported by Shingadia and coworkers a migrated free-floating catheter was colonized by three gram-negative pathogens which caused ten recurrent shunt infections. The boy was cured by endoscopic removal of the shunt fragment [18]. Vougioukas et al. observed the patient with retained ventricular catheter infected with gram-positive Propionibacterium acnes complicated by asymptomatic brain abscess which was removed during surgical craniotomy [19]. In three other cases the Staphylococcal infections were identified [1,9]. Khan et al. presented the patient with ventricular migrated catheter coexisting with asymptomatic brain abscess, both of which were removed during craniotomy procedure without any difficulties [9]. Last but not least, Vajramani et al. reported the case of the patient who underwent left occipital image-guided craniotomy and a successful removal of the retained catheters [1]. Based on the cases above, the authors postulate a removal of a retained ventricular catheter from every patient in order to prevent immediate or delayed infection complications.

\section{Acknowledgements}

The authors thank Patrycja Herbowska for help in the English translation of this manuscript.

\section{REFERENCES}

[1] G. V. Vajramani, G. Jones, R. Bayston and W. P. Gray, "Persistent and Intractable Ventriculitis Due to Retained Ventricular Catheters," British Journal of Neurosurgery, Vol. 19, No. 6, 2005, pp. 496-501. doi: $10.1080 / 02688690500495299$

[2] E. Nowosławska, L. Polis, D. Kaniewska, W. Mikołajczyk, J. Krawczyk, W. Szymański, K. Zakrzewski and J. Pod- 
ciechowska, "Neuroendoscopic Technique in the Treatment of Complex Hydrocephalus in Children," Polish Journal of Neurology and Neurosurgery, Vol. 37, No. 1, 2003, pp. 99-111.

[3] R. Acharya, A. Bhutani, H. Saxena and V. S. Madan, "Complete Migration of Ventriculoperitoneal Shunt into the Ventricle," Neurological Sciences, Vol. 23, No. 2, 2002, pp. 75-77. doi:10.1007/s100720200029

[4] T. Yamazaki, S. Shimizu, T. Sagiuchi, T. Iwasaki, S. Utsuki, S. Suzuki and K. Fujii, "Intractable Seizures Associated with Proximal Migration of a Ventriculoperitoneal Shunt," Neurol Med Chir (Tokyo), Vol. 45, No. 11, 2005, pp. 600603. doi: $10.2176 /$ nmc. 45.600

[5] A. de Stefani, L. de Risio, S. R. Platt, L. Matiasek, A. Lujan-Feliu-Pascual and L. S. Garosi, "Surgical Technique, Postoperative Complications and Outcome in 14 Dogs Treated for Hydrocephalus by Ventriculoperitoneal Shunting," Veterinary Surgery, Vol. 40, No. 2, 2011, pp. 183191. doi:10.1111/j.1532-950X.2010.00764.x

[6] H. Chen, J. Riva-Cambrin, D. L. Brockmeyer, M. L. Walker and R. W. Kestle, "Shunt Failure Due to Intracranial Migration of BioGlide Ventricular Catheters," Journal of Neurosurgery: Pediatrics, Vol. 7, No. 4, 2011, pp. 408-412. doi:10.3171/2011.1.PEDS10389

[7] A. Agarwal and A. Kakani, "Shunt Malfunction Due to Proximal Migration and Subcutaneous Coiling of a Peritoneal Catheter," Journal of Neurosciences in Rural Practice, Vol. 1, No. 2, 2010, pp. 120-121.

[8] A. Ahmed, G. Sandlas, P. Kothari, D. Sarda, A. Gupta, P. Karkera and P. Joshi, "Outcome Analysis of Shunt Surgery in Hydrocephalus," Journal of Indian Association of Pediatric Surgeons, Vol. 14, No. 3, 2009, pp. 98-101. doi:10.4103/0971-9261.57700

[9] S. A. Khan, A. Gretchel, H. Govender and B. Hartzenberg, "Brain Abscecss and Granuloma Formation as Late Complications of Retained Ventricular Catheter," Neurology India, Vol. 57, No. 4, 2009, pp. 489-492. doi:10.4103/0028-3886.55604

[10] E. O. Komolafe, A. A. Adeolu and M. A. Komolafe, "Complete Intraventricular Migration of a Ventriculo-Peritoneal Shunt-A Case Report and Brief Literature Review," African Journal of Neurological Sciences, Vol. 26, 2007, pp. 69-74.

[11] T. D. Nadkarni, R. K. Menon, N. N. Dange, K. I. Desai and A. Goel, "Cranial Migration of Complete VentriculoPeritoneal Shunt Assembly," Journal of Clinical Neuroscience, Vol. 14, No. 1, 2007, pp. 92-94. doi:10.1016/j.jocn.2005.12.027

[12] V. Parihar, Y. R. Yadav, N. Pandey and D. Sharma, "A
Rare Case of Complete Intraventricular Migration of Ventriculo-Peritoneal Shunt," Journal of Pediatric Neurology, Vol. 7, 2009, pp. 419-421.

[13] C. U. Pereira and E. A. S. Santos, "Intracranial Migration of a Ventriculo-Peritoneal Shunt Catheter," The Internet Journal of Pediatrics and Neonatology, Vol. 4, No. 2, 2005.

http://www.ispub.com:80/journal/the-internet-of-pediatric s-and-neonatology/volume-4-number-2/intracranial-migration-of-a-ventriculo-peritoneal-shunt-catheter.html

[14] V. Saggar, A. Gandhi and R. S. Mittal, "Abnormal Migration of the Ventricular End of Shunt Tip into the Pitutary Fossa," The Internet Journal of Neurosurgery, Vol. 5, No. 2, 2009.

http://www.ispub.com:80/journal/the-internet-journal-ofneurosugery/volume-5-number-2/abnormal-migration-ofthe-ventricular-end-of-shunt-tip-into-the-pitutary-fossa.ht $\mathrm{ml}$

[15] W. B. Schueler, T. B. Mapstone and N. L. Gross, "Migration of a Ventricular Tapping Reservoir into the Third Ventricle," Journal of Neurosurgery: Pediatrics, Vol. 6, No. 6, 2010, pp. 550-552. doi:10.3171/2010.9.PEDS1023

[16] G. Sengul, Y. Tuzun, H. H. Kadioglu and I. H. Aydin, "Complete Intraventricular Unisystem Ventriculoperitoneal Shunt Migration," Pediatric Neurosurgery, Vol. 41, No. 6, 2005, pp. 337-338. doi:10.1159/000088738

[17] S. Sharma and D. K. Gupta, "Intraventricular Migration of an Entire VP Shunt," Indian Pediatrics, Vol. 42, 2005, pp. 187-188.

[18] D. Shingadia, J. Grant, M. Bendet, S. T. Shulman and R. Yogev, "Multiple Recurrent Gram-Negative Cerebrospinal Fluid Shunt Infections Associated with a Patient with a Retained Ventricular Foreign Body," Pediatric Neurosurgery, Vol. 31, No. 3, 1999, pp. 155-158. doi: $10.1159 / 000028852$

[19] V. I. Vougioukas, F. Feuerhake, U. Hubbe, P. Reinacher and V. Velthoven, "Latent Abscess Formation Adjacent to a Non-Functioning Intraventricular Catheter," Child's Nervous System, Vol. 19, No. 2, 2003, pp. 119-121.

[20] B. E. Weprin and D. M. Swift, "Complications of Ventricular Shunts," Techniques in Neurosurgery, Vol. 7, No. 3, 2002, pp. 224-242. doi:10.1097/00127927-200207030-00010

[21] S. L. Parker, F. J. Attenello and D. M. Sciubba, "Comparison of Shunt Infection Incidence in High-Risk Subgroups Receiving Antibiotic-Impregnated Versus Standard Shunts," Child's Nervous System, Vol. 25, No. 1, 2009, pp. 77-83. doi:10.1007/s00381-008-0743-0 